\title{
ELINOR OSTROM, A PREMIAÇÃO DA VISÃO UNIFICADA DAS CIÊNCIAS HUMANAS
}

\author{
Amilcar Baiardi*
}

\begin{abstract}
Sempre houve preocupações no sentido de estabelecer uma conexão histórica e paradigmática entre a sociologia, a economia e a política, sustentando a unificação dos campos científicos e trazendo de volta aquilo que para Weber era a Ciência Social como "Ciência da Realidade", voltada para a compreensão da significação cultural atual dos fenômenos e para o entendimento de sua origem histórica e que, para Marx, era a busca da totalidade, fundamental porque não seria possível compreender as partes sem uma visão do todo. Neste texto, explora-se esse "approach", focando a obra de Elinor Ostrom, vencedora do Prêmio Nobel de Economia de 2009, que sempre se recusou a ver a esfera das ciências humanas como uma "Torre de Babel", mas sim como um ambiente com amplas possibilidades de integração, sendo sua práxis um exemplo completo e eloquente de convergência e de síntese nas ciências sociais. Após o breve exame de alguns casos emblemáticos de tentativas de integração das ciências sociais, analisam-se a trajetória acadêmica de Elinor Ostrom e suas principais contribuições para as pesquisas sobre os recursos e bens de propriedade comum.

Palavras-Chave: propriedade comum, cooperação, interdisciplinaridade, instituições e governança.
\end{abstract}

\section{INTRODUÇÃO: a economia e as demais ciências sociais}

Talvez por uma concepção positivista da ciência que tinha seu instituidor, ou talvez porque a Academia Real das Ciências da Suécia dessa visão não tenha se distanciado quando flexibilizou a concessão do Prêmio Nobel, não se tenha estabelecido uma premiação para as contribuições cientificas no campo das humanidades. O denominado Prêmio Nobel de Economia não é pago com recursos da Fundação Nobel, mas do Sveriges Riskbank, o banco central da Suécia. Foi essa instituição financeira que criou o Prêmio de Ciências Econômicas em memória de Alfred Nobel, cuja outorga é decidida pela Academia Real das Ciências da Suécia, junto com os concedidos nos campos da Física, da Química, da Medicina ou Fisiologia, da Literatura e da Paz ou da Diplomacia.

\footnotetext{
* Professor titular da Universidade Federal do Recôncavo da Bahia (UFRB) e dos Programas de Pós-graduação em Administração e em Ensino Filosofia e História da Ciência da UFBA.

Rua: Barão de Jeremoabo, s/n. Cep: 40170-115. Ondina
} - Salvador, Bahia - Brasil. amilcarbaiardi@uol.com.br
Provavelmente a mesma concepção da ciência impediu que fossem criados os prêmios para a Sociologia, para a Ciência Política, para a Antropologia, Psicologia Social, Filosofia, etc. Como afirma Sartori (1997, p.49) a vantagem da economia como ciência social é que ela logrou um ordenamento de sua linguagem. Para o autor, conceitos como valor, custo, preço e mercado não são redefinidos a cada momento. Por esse ou outro motivo, somente a economia foi colocada no mesmo plano das ciências naturais, no que tange ao reconhecimento para premiação pelas entidades promotoras do Prêmio Nobel expandido, ou com a inclusão da Economia.

Entretanto, para surpresa de muitos que esperavam que o denominado prêmio Nobel de Economia contemplasse, como fez na quase totalidade dos casos em mais de quarenta anos de existência, economistas alinhados com o pensamento econômico tradicional ou ortodoxo, o chamado mainstream, em 10 de dezembro de 2010 a premiação de economia é dada a Elinor Ostrom, junto com Oliver E. Williamson, que se distinguem exatamente por encontrar soluções econômicas fora 
do mercado, na sociedade. O que têm em comum esses cientistas sociais, considerados na premiação como economistas, mas cujo instrumental teórico e práxis não se situam predominantemente no campo da economia? Têm eles em comum a crença de que não se produz conhecimento pleno de fenômenos sociais com instrumentos de disciplinas isoladas, o que recentemente é reafirmado a partir de grupos de pesquisa que se propõem a estudar os sistemas complexos, a sociedade como um deles, a partir de equipes multidisciplinares (Beinhocker, 2007, p. 16-43)

Esta não é a primeira vez que a Academia Real das Ciências da Suécia premia alguém dentro do mundo da economia com uma visão bastante crítica do sistema de propriedade intelectual em vigor. Já houve anteriormente o caso de Joseph Stiglitz. Contudo, o de Elinor Ostrom é diferente. As suas investigações relativas ao modo como a apropriação de bens materiais e imateriais por uma pequena minoria podem prejudicar o conjunto da sociedade serviram de inspiração direta e indireta a vários movimentos defensores da mais ampla liberdade nesse grande ecossistema digital que é a Internet

No âmbito da denominada ciência econômica, a vertente 'economia política', dentro dos ramos contemporâneos do pensamento econômico, tem, vis-à-vis as demais correntes, um permanente diálogo com as ciências do grande campo das humanidades, visto que ela se vale de estudos interdisciplinares que se apoiam na sociologia, no direito e na ciência política para entender como as instituições, o corpo social e os contornos políticos influenciam a conduta dos mercados. A economia política tem inspiração clássica, quando do nascimento da ciência econômica, e estuda as relações entre a economia, a sociedade e o poder político dentro dos Estados, aprofundando-se em um amplo arco de teorias que vão desde as visões liberais até as marxistas. A inspiração na economia clássica justifica-se porque, naquele período, os economistas entendiam ser seu mister pensar de forma mais abrangente o papel da economia. Focalizavam desde a racionalidade na alocação dos fatores, na etapa de produção de bens, até a sua dis- tribuição e consumo, sem perder de vista que a circulação e o destino final do que fosse produzido dependiam da estrutura social e da repartição da renda. Estudos sobre a população, sobre as classes sociais, sobre a normatização do funcionamento da economia, etc. não estavam separados dos estudos econômicos propriamente ditos. Os casos de Adam Smith e Malthus são, nesse sentido, emblemáticos. A economia, então, tinha uma dimensão explicativa e outra prescritiva. A primeira interpretava os fenômenos econômicos e a segunda sugeria regras para que a economia funcionasse com o maior benefício possível para a sociedade como um todo.

Um distanciamento dessas concepções acontece a partir da chamada revolução neoclássica, que nasce com as obras Jevon, Menger, Walras, e posteriormente, Marshall, primeiros estudiosos do equilíbrio e do marginalismo que se desviaram, nas palavras de Labini (2006), dos supostos da economia clássica. A então nova economia adotou um paradigma que enaltecia a objetividade e que se inspirava em um novo modo de produzir ciência, que se generalizava nas ciências da natureza, distanciando-se das demais ciências sociais. Nesse novo approach, por exemplo, o consumo passou a ser apenas uma manifestação abstrata a interessar a etapa de realização, podendo ser ele indistintamente, para efeito da eficiência, o consumo dos capitalistas, dos trabalhadores, do governo ou de outros setores econômicos. O que passava a contar, na análise econômica, era tão somente a otimização do uso dos fatores para maximização da taxa de lucro.

O pensamento neoclássico se caracteriza por (i) individualismo metodológico; (ii) crença que oferta e demanda são leis universais que explicam todos os fenômenos econômicos; (iii); emprego da teoria da utilidade marginal; (iv); emprego da teoria da produtividade marginal da distribuição e (v) crença nos retornos crescentes de escala, requeridos para assegurar que todos os agentes produtivos sejam premiados de acordo com sua produtividade marginal e participação no produto total.

A influência do positivismo sobre essa ver- 
tente do pensamento econômico levou a exageros no esforço de assemelhar a economia às ciências da natureza, tornando-se a economia neoclássica hegemônica, não tanto por ser mais explicativa, mas por usar instrumentos de análise nascidos durante a revolução científica no século XVI e aplicados com sucesso às ciências da natureza. A economia neoclássica passou a ser uma área de conhecimento fechada, autônoma, que se valia de seus próprios elementos constitutivos para entender a realidade da produção e analisar endogenamente seu objeto de pesquisa. Nessa linha, pode-se afirmar que, dentre as vertentes contemporâneas na economia, a economia política e a economia institucional são as herdeiras mais legitimas da economia clássica.

\section{ANTECEDENTES NA VISÃO UNIFICADA DAS CIÊNCIAS HUMANAS}

Na história da construção das ciências humanas, usa-se essa definição por ela ser mais ampla que as ciências sociais e maior ainda que as ciências sociais aplicadas, em vários momentos, os protagonistas dessa tarefa não tinham a menor ideia se estavam escrevendo os fundamentos da economia, da sociologia ou mesmo da ciência política. Melhor, não distinguiam esses campos como contemporaneamente se faz e, certamente, estavam, concomitantemente, dando nascimento ou continuidade à economia, à sociologia e à ciência política. Marx (1982, p. 23), no prefácio de A Crítica da Economia Política, faz a apresentação do seu método de pesquisa e do seu plano intelectual de trabalho, que não foi executado além dos dois primeiros itens, permanecendo como intenções seus estudos sobre "A Síntese da Sociedade Burguesa no Estado", "As relações Internacionais e a Divisão do Trabalho", e "O Mercado Internacional e as Crises". Na ocasião, não fazia ideia de que seu legado fosse visto mais tarde como um compêndio de economia, de política ou de sociologia. Interessava-lhe apenas que fosse de utilidade para que a classe operária obtivesse dele diretrizes para a ação revolucionária (Instituto de Marxismo Leninismo do... 1983, p. 423-426).

A exemplo de Karl Marx, a Max Weber também não ocorria, com suas obra, contribuir mais ou menos para esta ou aquela ciência humana. Ademais, fazia uso sistemático de conceitos e categorias sociológicos, do mesmo modo que utilizava conceitos e categorias trazidas do campo da economia como da história. Tanto em Economia e Sociedade, obra iniciada em 1913/14 (Weber, 1997, p. 5-166), como em História Econômica (Weber, 2007, p. 7-54), fica evidente o domínio do autor sobre as denominadas ciências humanas e a facilidade com que transitava explicativamente no conhecimento conjunto desses campos do saber.

Não obstante recusasse ver, na base material da sociedade, na organização econômica, a determinante das manifestações subjetivas, das visões de mundo dos grupos sociais, Weber não negava que a organização produtiva, e dentro dela o comportamento dos agentes, exercia um papel na forma de pensar e interpretar a realidade. Sua diferença em relação a Marx residia, sobretudo, no dimensionamento dessa influência, na escala em que ela se verificava, e também porque percebia as condições subjetivas, principalmente a cultura, concorrendo para definir a organização econômica. Para Max Weber, tanto a ação, a inserção orgânica na produção, contribuía para a consciência, como esta era responsável pela ação individual ou coletiva na organização produtiva.

Um exemplo marcante de uso integrado de conceitos do campo da sociologia e do campo da economia para explicar condutas diversas de agentes sociais é dado por Weber (1979). Para o autor, que compara o comportamento, na Europa e nos Estados Unidos, do produtor familiar rural, o fato de o mercado ter precedido o surgimento do farmer americano faz com que ele, diferentemente do camponês europeu, não seja influenciado por decisões comunitárias e por vínculos tradicionais quando atua como agente econômico. O farmer, diferentemente do peasant como produtor, só se guia pelo mercado.

Essas contribuições seminais permitiram estabelecer inúmeras direções alternativas e con- 
traditórias, sustentando a possibilidade, se não de unificação das Ciências Sociais, mas sim de convergência, permitindo estreita parceria entre a Sociologia, a Economia e a Ciência Política e levando a uma síntese multidimensional tanto normativa como instrumental da ação e da ordem e a uma confluência das tendências analíticas geralmente tidas como incompatíveis: a interpretativista e a explicativa.

Contudo, não é necessário recuar entre 150 e 100 anos para mostrar a riqueza da abordagem interdisciplinar nas ciências humanas e como ela traz resultados significativos, tanto do ponto de vista epistemológico como de explicação da realidade. Na extensa obra de Paolo Sylops Labini, há demonstrações inequívocas de como ele extrapolou as fronteiras da economia para poder tratar o tema de forma mais completa, com interpretações mais ricas e com prescrições que demonstravam que ele transcendia o terreno da economia para ser mais preciso teoricamente e mais aderente à realidade.

Um dos trabalhos de sua autoria que mais contribuiu para difundir a fama de Labini como economista que recorria com frequência à sociologia como campo de saber foi Saggio sulle classi sociali, publicado pela primeira vez em 1974, seguido de várias re-edições. Esse texto de Labini teve uma história longa e complexa, uma vez que foi solicitado pelo mundo político e cultural da região do Piemonte italiano, o que se deu após uma série de conferências das quais participaram John Kenneth Galbraith, Evgenij Evtušenko, Herbert Marcuse e outros nomes de ressonância. Um dos veículos que publicou na integra esse trabalho de Labini foi o Quaderni di Sociologia (outubro-dezembro de 1972), e o fez com um título diferente, qual seja, Sviluppo economico e classi sociali in Itália. Para Labini (1988, p.7-10), o seu texto contribuiria para uma compreensão crítica da sociedade italiana e de seus problemas. Estudar a composição e a dinâmica das classes sociais era, portanto, para Sylos Labini, uma etapa obrigatória para compreender de que modo as reformas poderiam acontecer, fossem elas as reformas do Estado, da burocracia e das profissões, da economia, da universidade, etc. Sua obra, no geral, sub- sidiou a concepção de várias intervenções e políticas públicas e se utilizava de conceitos, categorias e mesmo de teorias provenientes do campo da sociologia e da ciência política.

Ainda de relevo na obra interdisciplinar de Labini (2007) foi também o livro Torniamo ai classici: produtività del lavoro, progresso técnico e sviluppo economico, no qual Labini retoma a ideia de que não se pode pensar a economia sem associar a produção com a distribuição para todas as classes sociais, privilegiando um enfoque sobre a economia do trabalho e recorrendo a dados e conceitos do campo da sociologia. Outro trabalho recente que, como o anterior, integrou suas últimas obras, já que ele faleceu em 2005, foi Miseria e sottosviluppo. Come Uscirne (Labini, 2007).

\section{AS VERTENTES CONCEITUAIS E TEÓRICAS DA PRÁXIS ACADÊMICA DE ELINOR OSTROM}

A leitura da obra de Elinor Ostrom oferece inúmeras pistas de suas inspirações, o que não significa dizer que ela não tenha transcendido essa influência e até mesmo avançado em relação à sua herança intelectual, aproximando-se de um sistema conceitual próprio em torno da ação coletiva. Além das matrizes clássicas - e, nesse caso, não se pode omitir as considerações de Marx sobre a cooperação voluntária simples para aproveitamento dos recursos da natureza e a cooperação complexa associada à transformação da produção artesanal em manufatureira e desta em indústria, contidas no livro 1 de $O$ Capital (1968, p. 370-385), e as de Weber sobre a ação coletiva e as normas (instituições) que aparecem em Economia e Sociedade (1997, p. 51-110), em Ética Protestante e Espírito do Capitalismo (1985, p. 155-182) e em História Econômica (2007, p. 151-258) -, há autores contemporâneos que exerceram influência e mesmo iluminaram epistemologicamente a trajetória de E. Ostrom. Esses cientistas sociais, de uma forma arbitrária em benefício de algum ordenamento, encontram-se no tema das instituições, de sua aná- 
lise e da governança por elas proporcionada e no tema da cooperação.

Mais definidamente no primeiro campo e com notoriedade em economia institucional, encontra-se Douglass C. North. As pesquisas de North (1990) foram decisivas no destacar o papel das instituições no desenvolvimento econômico, permitindo que pesquisadores como Coase e Willianson partissem daí para lançar os fundamentos da economia institucional, inclusive o conceito de custo de transação. Douglass North, ele mesmo membro de um departamento de ciência política, exercitou inúmeras vezes a convergência e a análise unificada nas ciências sociais. North era uma referência para E. Ostrom, por tê-la motivado para entender não só a natureza das instituições, mas o seu papel no nível micro, viabilizando a governança comum dos recursos naturais e produtivos. Ademais, contribuiu indiretamente para Elinor desenvolver o IAD, Institutional Analysis and Development, ferramenta que conferiu poder explicativo para suas pesquisas empíricas.

Ela, por sua vez, não passou desapercebida a ele, que, de certa forma, estimulou-a a organizar seus papers e a publicar um livro que veio a lume em 1990, com o título de Governing the commons: the evolution of institutions for collective action. Isso se deu quando North assistiu pela primeira vez a uma exposição de E. Ostrom na Washington University, no campus de St Louis, em 1986. Na ocasião E.Ostrom se encontrava imersa na execução do seu projeto plurianual e internacional sobre os recursos de propriedade comum, Common Pool Resources CPR, para o qual contou sistematicamente com financiamento de agências de fomento à pesquisa.

O estimulo dado por North se explica porque ele viu na pesquisa de Elinor a expressão de suas teses, na medida em que a autogestão de recursos naturais ou produtivos escassos só seria possível mediante a criação ou adoção de instituições, entendidas como criações humanas, para promover e favorecer o desenvolvimento. O que North pensara como análise de tendências históricas e agregados maiores se expressava no objeto de pesquisa de E. Ostrom, na realidade de comu- nidades rurais e urbanas em todo o mundo, que preservavam, utilizavam de modo sustentável os recursos naturais escassos e conduziam uma gestão democrática e coletiva de recursos produtivos insuficientes em termos de dotação por habitante. O referenciamento mútuo entre Douglass North e Elinor Ostrom e a crença de que suas obras se complementavam se emblematiza com a publicação, no mesmo ano, pela mesma editora, de Understanding institutional diversity (2005) por Elinor Ostrom e Understanding institutional change (2005) por Douglass C. North.

Ainda nesse mesmo campo, no do interesse pelas instituições e pelo papel e responsabilidade do Estado a fomentá-las, estava Vicent Ostrom, exprofessor, colega e esposo de Elinor, que, durante 30 anos, criticou com observações pertinentes o seu arcabouço teórico para enquadrar e analisar as experiências de gestão pública, público-privada e autogestão de recursos naturais e (ou) produtivos comuns. V. Ostrom tinha como principal interesse de pesquisa a análise institucional no manejo de bacias e de recursos hídricos e a eficiência do governo. Foram seus seminários que induziram a tese de $\mathrm{PhD}$ de Elinor, defendida em 1965, e consolidou seu interesse por pesquisas que focassem a ação coletiva. À medida que Elinor avançava, concentrando-se nos Common Pool Resources, CPR, a ponto de situar sua análise até no conhecimento como bem comum, Vicent passou a se interessar por outros temas, entre eles a administração pública, governo, negociação, etc.

O estudo da ação coletiva nos CPRs significava, para E. Ostrom, uma amalgama com a cooperação. Uma não poderia existir sem a outra e, por essa razão, ela buscou, ao lado da análise institucional, o aprofundamento no tema da cooperação.

Elinor interessou-se pelos fundamentos da cooperação e sua referência não poderia ser outra que Axelrod (1984 e 2004), que escreveu dois livros de grande impacto. Entre seu primeiro livro de 1984 e o segundo, cuja primeira edição em inglês é de 1997, passaram-se treze anos e, nesse período, aconteceu o colapso do chamado socialismo real, razão suficiente para o autor retomar a 
fundo o tema e ultrapassar a simplicidade do primeiro, que se baseava no paradigma do dilema do prisioneiro bi-pessoal e interativo e no tema da cooperação baseada na reciprocidade que pode evoluir e sustentar-se, mesmo entre egoístas. No segundo, Axelrod (2004, p.10) diz que vai além do paradigma do dilema do prisioneiro bi-pessoal e interativo, porque seus estudos o convenceram de que existem estratégias que automaticamente fazem avançar as bases da cooperação, resolvendo mal entendidos e fomentando a colaboração, com vistas a pôr em vigor normas que defendem os membros de um grupo social e constroem uma cultura compartilhada, baseada na influência mútua.

Outra marca do segundo livro é que ele está recheado de inúmeros casos de construção e autoconstrução de regras que conferem sucesso à empresa da cooperação. No primeiro livro, Axelrod ilustra a cooperação com informações científicas de que ela precede o aparecimento da espécie humana, é comum entre a mesma espécie e entre espécies diferentes, está associada coma possibilidade de sobreviver e evoluir na esfera dos seres vivos e se tornou parte da vida humana desde que ela surgiu, em parte porque está geneticamente condicionada e em parte porque é avaliada como a conduta mais adequada e que leva à reciprocidade.

Quando do segundo livro, Axelrod já havia entendido que, mesmo em situações de jogadores propensos a se comportarem como desertores no jogo baseado no dilema do prisioneiro, a cultura da cooperação já permitia comportamentos generosos de jogadores que seguiam fazendo escolhas de cooperar, mesmo em condições de adversidade, o que permitia a reconstrução, à frente, não só de novas oportunidades de cooperação, mas também de normas que ampliassem a propensão a cooperar e que, quanto mais disseminadas fossem, melhores resultados proporcionariam. A obra de Axelrod sobre a cooperação, recolhendo elementos que amparavam as expectativas teóricas e as evidências empíricas das pesquisas de Elinor Ostrom, não bastaram a essa pesquisadora. Ela foi em busca de outras fontes e referências sobre o tema da cooperação e, nesse caso, não para se apoi- ar, mas para refutar teses.

Esse é o caso de Mancur Olson (1999). Para esse autor, a ação coletiva com vistas a cooperar reside no interesse pessoal, individual, sendo esse o motivo pelo qual os grupos tendem a agir em favor de seus interesses como coletivos. Para Olson, o comportamento racional e centrado nos próprios interesses é considerado como a conduta mais comum, ou seja, pode ser generalizado, especialmente por razões econômicas. Entretanto, o autor chama a atenção para o fato de que os indivíduos racionais e centrados nos próprios interesses não agirão voluntariamente para promover seus interesses comuns ou grupais, a menos que haja condicionamentos para tanto, entre eles intervenções externas como a coerção.

Para Olson (1999), é comum verificar-se que quase todas as organizações têm seus interesses, o que constitui a razão de sua existência. Isso se observa tanto na esfera do Estado como da sociedade civil e vem de tempos remotos, embora haja diferenças de motivações para cooperar entre as sociedades primitivas e as associações voluntárias dos tempos atuais. Para o autor, o que uniria os impulsos de cooperação, tanto em uma época como em outra, seria o instinto. Na modernidade, por serem as necessidades mais complexas e mais difíceis de ser alcançadas ou supridas pelos grupos tradicionais, ocorreria uma maior complexidade na cooperação. Em continuação, Olson (1999) conclui que grupos menores são mais eficientes para conseguir um retorno coletivo, comparativamente a grupos grandes, nos quais existe uma diluição do benefício. Olson propõe uma tipologia de grupos de acordo com a eficiência em promover a ação coletiva e obter benefícios, sendo eles "exclusivos" e "inclusivos", "privilegiados", "intermediários" e "latentes". Os inclusivos são aqueles nos quais não há perdas diante de defecções e os exclusivos aqueles que requerem a cooperação do conjunto para alcançar resultados. No caso do grupo "privilegiado", o benefício coletivo dispensa a organização, sendo uma exigência no caso dos intermediários. O latente, por sua vez, seria aquele no qual não existiria prejuízo para qualquer membro no caso 
da ação coletiva não gerar benefício.

Olson (1999) considera que os incentivos econômicos não são os únicos passíveis de gerar interesse pela cooperação, pois o prestígio, o respeito e a amizade podem também constituir motivações para a ação coletiva com vistas à cooperação. O autor sugere que, além dos benefícios tangíveis, existem outras motivações, como as sanções e as recompensas, que funcionam visando a fortalecer a coesão e ensejar a cooperação.

Uma abordagem divergente da de Olson e muito próxima daquela que aparece no segundo livro de Axelrod (2004) sobre os fundamentos da cooperação se encontra em Douglas (1998), que explora as questões de solidariedade e de cooperação entre os membros de um grupo, procurando estabelecer relação entre o pensamento individual e o pensamento dominante nas instituições das quais eles fazem parte. O conceito de instituições apresentado por Douglas (1998) diz respeito aos valores compartilhados por um grupo social qualquer, aquilo que se denomina também como intersubjetividade entre os indivíduos, sem que tenha o mesmo grupo a obrigatoriedade de apresentar uma estrutura organizacional para isso. Esse entendimento tem como matriz os trabalhos de North (1990) e está intimamente ligado ao conceito de cultura. A fundamentação de Douglas (1998) está no fato de não ser qualquer "ônibus lotado" ou ajuntamento aleatório de pessoas que merece o nome de sociedade. É imperativo que, além disso, exista, entre seus membros, algum pensamento e algum sentimento que se assemelhem, o que vai além da existência legal. Para a autora, o senso de pertencimento, a identidade, transcende a mecânica inserção no local de trabalho ou afiliação religiosa. Embora esses condicionamentos possam favorecer a cooperação, é necessário que o indivíduo calcule racionalmente aquilo que melhor atende a seus interesses e aja de acordo com isso, o que não exclui a contribuição para o bem público com a generosidade, até mesmo sem hesitações, sem a intenção óbvia de obter um benefício próprio.

Douglas (1998) diverge da visão de Durkheim e Fleck, que afirmam ser o engajamento uma subordinação dos interesses individuais a um todo social mais amplo. A autora sugere que essa visão se apoia demasiadamente na religião, segundo Durkheim, ou na possibilidade de um estilo de pensamento reinar soberanamente sobre o universo de pensamentos, segundo Fleck. Para Douglas (1998), ambas as proposições parecem inconsistentes. Segundo a autora, a tomada de decisão, na linha de promover e participar da ação coletiva, está intimamente ligada ao processo de cognição. Nesse sentido, sugere que o enfoque neoinstitucionalista é aquele que percebe o indivíduo como um ser racional, que toma suas decisões baseado no conhecimento que possui sobre um determinado assunto, estando tal conhecimento, por sua vez, atrelado intimamente aos valores institucionais que influenciam decisivamente a sua tomada de decisão.

Nessa situação, a racionalidade do indivíduo não é maximizadora, simplesmente, utilitarista mecanicamente, mas voltada para a realidade institucional da qual faz parte.

Douglas (1998) também discorda de Olson no sentido de reconhecer e valorizar a possibilidade de maior engajamento de indivíduos cujo universo de ações se prende a interesses particulares, desde que, na coletividade, tenham sido criadas instituições que dominam o processo que antecede a tomada de decisão. Isso porque, para ela, é a instituição a responsável por promover a solidariedade. É a 'solidariedade institucional' a responsável pela ação coletiva não-compulsória. Para Douglas (1998), os indivíduos compartilham seus pensamentos e, até certo ponto, harmonizam suas preferências e coordenam suas ações. Sendo assim, eles não têm outros meios de tomar as grandes decisões a não ser na esfera das instituições que eles constroem.

Embora as visões de Douglas (1998) sobre os fundamentos e sobre as possibilidades da cooperação se aproximem das de Ostrom $(1990,2005)$, inclusive no que tange à influencia de North (1990, 2005) sobre o papel das instituições, não há, na obra de E. Ostrom, evidência de diálogo entre ela e Mary Douglas, embora seja possível supor, pela 
contemporaneidade, um conhecimento recíproco de produção acadêmica. A maior evidência dessa possibilidade é o approach de Elinor sobre as instituições que são criadas para contornar situações de risco, quando se trata da cooperação com vistas à sobrevivência, situação na qual as ações dos indivíduos ou das instituições por eles criadas atenuam os problemas e evitam deserções.

Na sua incursão sobre a teoria da cooperação, sobre seus fundamentos, influenciada por Axelrod e provavelmente por Douglas e outros, E. Ostrom avança e refuta as ideias de Olson, cuja essência é identificar as motivações das ações coletivas em interesses individuais, sobretudo econômicos, sem negar a possibilidade frequente da "tragédia dos bens comuns", como definida por Hardin (1868). Isso fica mais claramente demonstrado em Hess e Ostrom (2009), quando, indiretamente, também criticam a obra de Hardin, criando uma designação metafórica para, simultaneamente, discordar de Hardin e de Olson. Ao conceituar não como "a tragédia dos bens comuns" a presença de free riding, que, agindo exclusivamente no interesse próprio, ameaça um recurso coletivo, a autora diz que o fenômeno se assemelharia mais a uma "tragicomédia dos bens comuns", uma vez que a análise de qualquer que seja o bem comum deve levar em conta as regras, as decisões e os comportamentos das pessoas nos diferentes grupos que se relacionam no compartilhamento de recursos (2009,

p.13). Ostrom diz que a "prosa" de Hardin contém uma série de teses repetidamente negadas pelos estudiosos dos bens comuns, tais como existir o livre acesso dos bens comuns, haver comunicação limitada, a condição predominante dos usuários ser a de free riding, ou seja, agir sempre no uso do bem comum egoisticamente, e oferecer somente duas alternativas para resolver a "tragédia": privatização ou estatização dos bens comuns.

A grande diferença entre as abordagens de Hardin e Olson, de um lado, e de E. Ostrom, de outro, é que a última dedicou mais de 30 anos à pesquisa sobre as regras dos usos de bens coletivos e, ao procurar compreendê-las, deu especial ênfase aos fundamentos da cooperação entendida como essencial para sobrevivência, constituindose em necessidade imperiosa de encontrar coletivamente soluções para um patrimônio compartilhado, do qual todos dependem. Para Elinor Ostrom (2005, 2006), a ação coletiva, indutora de convenções e instituições capazes de oferecer a alternativa de gestão comum diante das soluções mais triviais ou mais complexas, é retroalimentada permanentemente por essas convenções e instituições, relegando a exceção às soluções oferecidas pela coerção, leia-se Estado, ou pelo mercado, leia-se a firma.

Ostrom (2006) não nega a possibilidade de a coerção, a solução hobbesiana, não vir a ser eficiente na organização da diversidade das ações humanas, ou de os estímulos materiais, a solução de mercado, não poderem também fazer convergir ações. Entretanto, o que a autora defende é que, na maioria dos casos em que um determinado recurso natural, ou mesmo um bem de capital, é propriedade coletiva, existe a possibilidade de, com menor custo e com maior garantia de preservação, serem construídas regras para um desfrute coletivo e sustentável. Isso dependeria unicamente da capacidade de a comunidade criar instituições adequadas por meio da ação coletiva. As condições que levariam a soluções que não fossem nem de mercado e nem de Estado seriam aquelas que favorecessem a criação de instituições estáveis de autogoverno, desde que problemas de suprimento, de credibilidade e de monitoramento fossem resolvidos. Em outras palavras, se as comunidades não são pressionadas por razões de subsistência a desfrutar predatoriamente os recursos, se há possibilidade de fomentar a credibilidade e a confiança entre os integrantes e se são aceitas regras de monitoramento com vistas a dividir custos, benefícios e distribuir responsabilidades, existiriam condições de criação de um autogoverno de bens comuns.

Analisando as contribuições de autores que a precederam, inclusive Olson, quando escreveu A Lógica da Ação Coletiva (primeira edição em 1965), Ostron vê que tanto esse autor, como os outros que abordaram "o dilema do prisioneiro" e da "tragédia dos comuns", deram demasiada ênfase à ação que o insubmisso ou free rider pode ter 
em desacreditar o esforço coletivo. Ela informa que estudos mais recentes são menos categóricos e pessimistas em relação às restrições ou condições especiais nas quais a ação coletiva visando ao bem comum prospera.

Ostrom (2006) propõe que os modelos referidos por autores que a precederam não esgotam as possibilidades de entender os móveis da cooperação e que a institucionalização pode assimilar o que há de bom na proposta de governo ou na proposta de mercado, trazendo soluções mais justas e mais criativas. A autora aduz dezenas de casos de cooperação precedidos de institucionalizações que deram certo em bacias hidrográficas, em florestas, em áreas de pesca, em superfície de terra etc.

\section{A TRAJETORIA ACADÊMICA DE ELINOR OSTROM}

Ao se prospectar sobre o que seria a motivação primeira, as raízes, os fundamentos da escolha do objeto de pesquisa de Elinor Ostrom, conviria indicar que, no âmbito das ciências sociais, seu interesse precípuo foi o de buscar contribuir para a construção da tese de que os bens tidos como comuns devem ser vistos como tal. Como consequência dessa visão, mas ulterior e como parte indissociável dessa crença que ela decidiu compartilhar em sua práxis acadêmica, está a convicção de que bens comuns são tão mais preservados como tal quanto mais passíveis estejam de uma gestão compartilhada. Suas motivações primeiras foram essas e em relação a elas não houve nenhum "detour" na sua vida acadêmica.

Segundo Elinor, sua obra é uma sucessão, às vezes não tão linear, não tão temporalmente distribuída ou lógica como deveria ser, de trabalhos que aparecem a partir de 1965. Esse foi o ano em que defendeu sua tese de doutorado, a qual foi profundamente influenciada por uma série de seminários que ocorreram na Universidade da Califórnia, no Campus de Los Angeles, conduzidos por Vicent Ostrom, que viria a ser colega muito próximo e marido. Na ocasião, o interesse de E. Ostrom era a ação coletiva de uma série de agentes produtivos, o que teria levado ao surgimento de inúmeras empresas e intervenções públicas que bloquearam o processo de intrusão salina que estava comprometendo os mananciais de água doce da área metropolitana de Los Angeles. Suas pesquisas relacionadas à tese de doutorado mostravam que arranjos institucionais tiveram sucesso em evitar uma catástrofe econômica, que seria a invasão de bacias de água doce por águas do Oceano Pacífico. Nessa pesquisa, já se combinava o interesse pela análise institucional com a ação coletiva e com a gestão de bens comuns.

Nessa primeira fase, na década de setenta do século passado, quando ainda não se esboçara sua autonomia plena como pesquisadora, Elinor publica trabalhos em parceria com Vicent, focando problemas dos serviços urbanos e economias públicas em áreas metropolitanas. Dentre eles, os mais conhecidos foram "Public goods and public choices" e "A theory for institutional analysis of common pool problems", publicados ambos em 1977 (Ostrom, 2006).

Quando ainda na condição de jovem professora, no início década de oitenta do século passado, ela é convidada como "visiting fellow" pelo Centro de Pesquisas Interdisciplinares da Universidade de Bielefeld, Alemanha, para apresentar seminários sobre aprendizado organizacional, baseados em suas pesquisas sobre as regras estabelecidas pelos usuários de águas subterrâneas nas bacias do sul da Califórnia, Elinor ingressa em uma nova fase de produção intelectual e reconhecimento público. Os seus pares em Bielefed estavam desejosos de saber porque, 15 anos após suas pesquisas, os sistemas de autogoverno continuavam operantes. A resposta de Elinor era que isso sucedia porque os sistemas de autogoverno daqueles bens comuns foram concebidos e implantados de modo tão adaptado à realidade, que não só sobreviveram como melhoraram ao longo dos anos (Ostrom, 2006).

Voltando à Califórnia, Elinor orientou uma tese sobre sustentabilidade dos sistemas por ela estudados (Blomquist, W. "Geting Out of the Trap: 
Changing an Endangered Commons to a Managed Commons”. Ph.D. dissertation, Indiana University) e realizou mais 12 pesquisas financiadas pelo U.S. Geological Survey, visando a identificar que fatores estavam de modo bem sucedido associados à evolução de novas instituições e garantindo a sustentabilidade e a equidade dos usuários. Essa sucessão de pesquisas ensejou uma coleção de 8 volumes publicada com o título de The Performance of Groundwater Management, o primeiro publicado em 1988 e o último em 1990. Nesse período, Elinor passa a fazer parte do quadro de docentes da Universidade de Indiana.

Segundo ela, todos esses estudos empíricos foram essenciais para entender como as instituições são criadas e operam, mas não são suficientes para desenvolver uma ampla teoria de arranjos institucionais relacionada com a efetiva governança e gestão dos recursos de propriedade comum. Para avançar teoricamente, seria necessário obter informações similares de outras experiências, o que proporcionaria ampliação da base empírica necessária para melhorar seu entendimento teórico sobre como as instituições trabalham e como os indivíduos mudam suas próprias instituições.

A oportunidade de começar a discutir com outros pesquisadores dos Estados Unidos e de vários outros países surge com a promoção pela Academia Nacional de Ciências dos EEUU de um painel intitulado "Common Property Resource Management” em 1985. Os papers do evento deveriam não somente analisar como eram administrados os recursos de propriedade comum, CPRs, mas também quais as regras de entrada e permanência nesses sistemas, que tipos de interação existiam e quais os benefícios obtidos. Finalizado o evento, Elinor se deu conta de dois fatos. O primeiro era a existência de inúmeras pesquisas sobre o tema realizadas com rigor e por um período de tempo apreciável, em várias partes do mundo. O segundo era a diversidade de situações, tanto setoriais como territoriais, muitas delas com detalhada descrição de estratégias de apropriação dos recursos de propriedade comum, CPRs, que foram adotadas.
Com ajuda de colegas da Universidade de Indiana, Elinor mapeou mais de 100 casos entre cerca de 1000 relatados e selecionou aleatoriamente certo número deles, que foram visitados, a essa altura, com outros financiamentos, grants, de outras agências. Nos casos separados para serem escrutinados, Elinor constatou que as disciplinas representadas na bibliografia eram sociologia rural, antropologia, história econômica, ciência política, florestas, irrigação, pesca, geologia-mineralogia e ecologia humana (Ostrom, 2006).

Dessas visitas Elinor pretendia recolher várias respostas, entre elas como a exploração dos CPRs pode ser organizada em uma forma que evite o consumo excessivo e um elevado custo de administração. Queria também provar que as alternativas não eram somente a privatização e a estatização e que existia a alternativa de autogoverno. Sua amostra incluía experiências nas montanhas da Suíça e do Japão, de áreas pesqueiras da Turquia e do Canadá, de florestas na África e na Ásia etc. e encontrou organizações estáveis e vastas evidências de casos de sucesso e de insucesso. Baseando suas conclusões sobre comparações de fontes de sucesso e de fracasso em termos de autogoverno, Ostrom descreveu algumas das fundamentais características dos sistemas de exploração dos CPRs, que incluíam a) a estrutura do bem ou recurso; b) os atributos e comportamentos dos apropriadores; c) as regras utilizadas na apropriação e na exploração e d) os produtos, benefícios, resultantes para os apropriadores.

Com esses elementos, a pesquisadora desenvolveu um método de codificação para transformação de dados qualitativos em grandezas quantitativas, conduzindo, a partir daí, um exercício teórico que a levou ao desenvolvimento do método denominado Institutional Analysis and Development, IAD, apresentado pela primeira vez no capítulo 6 do seu livro de 1990, considerado pela autora "relatório de andamento", não ainda com essa designação que viria depois, mas como "uma estrutura para análise da auto-organização e do autogoverno". Os componentes dessa estrutura eram problemas de suprimento (logística), com- 
promisso credível, monitoramento mútuo, escolhas institucionais, compartilhamento de normas e outras oportunidades, processos de mudanças institucionais, previsão de mudanças institucionais e avaliação de custos e benefícios. Na apresentação da primeira versão do IAD, Ostrom (2006, p. 214), lança um desafio à comunidade de pesquisadores em ciências sociais. O desafio era o de produzir um modelo analítico capaz de dar conta das diversidades nas explorações dos recursos de propriedade comum, o qual levasse em conta os problemas e condicionantes internos e externos e a dinâmica, em termos de arranjos e ajustes concebidos e implantados nos processos produtivos. Nesse capítulo, ela alude, por meio de uma citação, à grande dificuldade de descrever e analisar experiências nas quais são permanentes as pressões governamentais para transferir a governança dos CPRs para empresas ou para o Estado, em um quadro no qual os indivíduos não se julgam aptos para "assumir as rédeas" de uma experiência de CPRs.

O IAD foi debatido tanto na Universidade de Indiana como fora desse ambiente, inclusive em uma passagem de Ostrom por Harvard em 1988. Ela também agradece, nesse particular, a Larry Kiser, Sue Crawford, Roy Gardner e James Walker, com os quais compartilhou ideias, além de elencar dezenas de colegas que com ela contribuíram ao criticar, dar sugestões para a consolidação do IAD como para o conjunto de sua obra.

O IAD permitiu a Ostrom entender as diversas estruturas da interação humana quando frente a recursos de propriedade comum, CPR, detalhar e relacionar o conjunto dessas ações, estudar as ações e situações em laboratórios, mediante simulação de comportamentos, e promover a análise da animação institucional. Os casos mais recentes de recursos de propriedade comum, CPRs, estudados por Ostrom foram posteriormente apresentados por ela em uma série de seminários em universidades e institutos, ocasiões nas quais ela tanto melhorava, refinava a eficiência do IAD, como promovia, fora da universidade de Indiana, discussões consideradas cada vez mais como oportunas, mais contemporâneas e capazes de despertar maior interesse internacional na comunidade de ciências sociais.

Em seu périplo, Ostrom esteve no Max Planck Center for the Study of Common Goods, no Sanford School of Public Policy na Universidade de Duke, no Department of Pollitical Science da Universidade da Califórnia, participou do WalkerAmes Lectures Series na Universidade de Washington, estando ainda na Universidade de Kathmandu, Universidade de Michigan, Purdue University, entre outras (Ostrom, 2005).É durante esse incansável esforço de compartilhar conhecimento que se dá aquilo que, segundo Bollier (2009), seria o desenvolvimento de um paradigma de pesquisa. O conhecimento gerado por Ostrom, parceiros e seguidores adquiriu tal poder explicativo, "power prediction", inclusive por meio do IAD, que se passou a defini-lo usando uma categoria khuniana trazida da história e da filosofia da ciência, inspirada na obra de Thomas Khum (1970), o de paradigma da gestão do bem comum.

Em seu último livro como única autora, Ostrom (2005) faz um balanço da relação direta que existe entre a ação humana e as instituições, dentre elas a ação coletiva, a cooperação. Nessa obra, a autora deixa claro que não são as instituições que explicam o comportamento humano em todos os casos e em todas as situações. Um número relativamente grande de fatores entra nesse jogo. Contudo, quando se trata de cooperar para o bem comum, sem sombra de dúvidas, a concentração, a saturação de regras que reforçam comportamentos proativos e ampliam a confiança têm um poder de explicação maior. Semelhantemente a Douglas (1998), com relação ao papel-chave das instituições, mas diferentemente no que diz respeito ao nível de impregnação delas na vida em sociedade, Ostrom (2005) refere-se à essencialidade de instituições bem construí-das, resultado de esforços policêntricos para lidar com as situações mais dramáticas, mais críticas, gerando robustos mecanismos de governança de recursos e com capacidade de resistir a ameaças para dar uma dimensão de sustentabilidade à ação coletiva. 


\section{A MAIS RECENTE CONTRIBUIÇÃO DE ELINOR OSTROM E A DIFUSÃO DO SEU PENSAMENTO NO BRASIL}

O mais recente desafio de Ostrom foi ampliar o conceito de recursos de propriedade comum e levar a estrutura analítica do IAD para ser aplicada ao conhecimento em si, como bem comum. Em Hess e Ostrom (2009), tem-se uma caracterização do conhecimento como bem comum, seguida de uma adaptação da estrutura analítica do IAD para utilização desse bem, cada vez menos tangível, mais virtual.

A proposta da obra organizada e escrita por Ostrom em parceria com outros autores é a de proteger os bens comuns do conhecimento. Na obra, toda a parte segunda é dedicada a como proceder para reduzir os casos de "deserção" e privatização na gestão dos bens comuns do conhecimento e evitar atitudes individualistas tipo free riding. Para as autoras e demais co-autores da obra, na governança do bem comum do conhecimento, visto que ele, em essência, é predominantemente um recurso de propriedade comum, todos os esforços do governo e da sociedade civil devem estar voltados para proteger, sustentar, financiar e ampliar esse tipo de ativo ou patrimônio.

Essa ação deveria se concentrar nas bibliotecas e fontes de informação, no sentido de tornálas cada vez mais completas e abertas aos usuários por ofício, pesquisadores e outros profissionais, como ao grande público. A ampliação dos bens comuns deve também contemplar, para os autores, novas formas de gestão, uma vez que, com o World Wide Web, as bibliotecas digitais deixam de ser geridas unicamente por bibliotecárias e profissionais de ciência da informação para serem geridas também por qualquer um que tenha conhecimento sobre um argumento e competência em tecnologia da informação.

Essa ação não deve, em nenhuma circunstância, significar desestímulo à propriedade intelectual. Ao contrário, por meio de institucionalidades, poder-se-ia concomitantemente, apoiar e proteger a legítima propriedade intelectual que remunera o pes- quisador e, ao mesmo tempo, disponibilizar o conhecimento para quem dele necessite.

Uma fantástica e futurista proposta contida na obra é a de um mertonianismo liberado (Boyle, 2009). O texto se inspira nos trabalhos de Robert King Merton (1973) que, ao tempo em que preconizava um grande rigor na avaliação dos trabalhos científicos, enaltecendo as rotinas acadêmicas de peer review, defendia que a pesquisa e a difusão do conhecimento fossem cada vez mais livres. Segundo Boyle, somente na contemporaneidade, quando, de fato, o conhecimento se torna um bem comum cada vez mais livre, o ideal de Merton se concretiza. Os projetos de bibliotecas digitais de livre acesso, como a National Science Digital Library dos EE UU, são o exemplo de disponibilização livre do conhecimento.

Surpreendentemente, até 2007, nada de Elinor Ostrom havia sido publicado no Brasil. Nesse ano, em inglês, são publicados no Brasil "The challenge of crafting rules to change open access resources into managed resources" $\mathrm{e}$ "The governance challenge: matching institutions to the structure of social-ecological systems" (Ostrom 2007a; 2007b). Isso se dá em um quadro de divulgação de trabalhos de autores nacionais e estrangeiros que deram contribuições significativas na análise das instituições para o desenvolvimento econômico. Embora esses trabalhos de Ostrom não sejam considerados os de maior impacto, eles foram bem acolhidos no contexto do evento, que tinha um viés para focar o papel das instituições no desenvolvimento sustentável e a governança na gestão dos recursos naturais de propriedade comum. Em português, é publicado em 2009, em coautoria com Moran, "Ecossistemas florestais" (Ostrom; Moran, 2009). Trata-se de livro que reúne os resultados de um projeto de pesquisa de larga escala e multidisciplinar, desenvolvido em mais de doze países e em cerca de oitenta locais diferentes. O projeto concentrou-se em investigar as mudanças na cobertura do planeta e o uso da terra em regióes de florestas, como as duas principais causas das alterações ambientais globais, e em entender por que algumas áreas florestais flores- 
cem, mesmo com a presença de alta densidade e atividade humana, enquanto outras definham e desaparecem.

A riqueza e a complexidade da obra de Elinor Ostrom ainda estão por ser reconhecidas no Brasil. A contribuição para análises teórica e para investigações empíricas, no que concerne aos usos de bens e recursos comuns, serão evidentes e poderão ensejar a adoção dos paradigmas das categorias teóricas que ela desenvolveu.

(Recebido para publicação em agosto de 2010)

(Aceito em janeiro de 2011)

\section{REFERÊNCIAS}

AXELROD, R. The evolution of cooperation. New York: Basic Books, 1984. 241 p.

La complejidad de la cooperación: modelos de cooperación y colaboración basados en los agentes. Buenos Aires: Fondo de Cultura Economica, 2004. 278 p.

BEINHOCKER, Eric D. The origin o $f$ wealth. Boston: Harvard Business School Press, 2007. 527 p.

BOLLIER, D Lo sviluppo del paradigma dei beni comuni. In: HESS, C.; OSTROM, E. (Org.) La conoscenza come bene comune. Torino: Bruno Mondadori, 2009. 409 p.

BOYLE, J. Merton Liberato? Acesso libero e decentralizzato a materiali culturali e scientifici. In: HESS, C.; OSTROM,

E. (Org.) La conoscenza come bene comune. Torino: Bruno Mondadori, 2009. 409 p.

DOUGLAS, Mary. Como as instituições pensam. São Paulo: EDUSP, $1998.144 \mathrm{p}$

INSTITUTO DE MARXISMO LENINISMO DO CC DO PCUS. Kalr Marx, biografia. Lisboa: Edições Avante, 1983. $799 \mathrm{p}$.

HARDIN, G. The tragedy of commons. Science, s.l., $\mathrm{n}$ 162, p. $1243-1248,1868$.

HESS, C.; OSTROM, E. (Org.) La conoscenza come bene comune. Torino: Bruno Mondadori, 2009. 409 p.

KUHN, T.S. The structure of scientific revolutions. Chicago: The University of Chicago Press, 1970. 210 p.
MARX, K. Para a crítica da economia política. São Paulo: Abril Cultural, 1982. 242p.

O capital, Livro 1, v.1. Rio de Janeiro: Civilização Brasileira, 1968. 579p.

MERTON, R.K. The sociology of science: theoretical and empirical investigations. Chicago: University of Chicago Press, 1973. 605p.

NORTH, D. C. Institutions, institutional change and economic performance. New York: Cambridge University Press, 1990. 151 p.

Understanding institutional change. Princeton: Princeton University Press, 2005. 245p.

OLSON, M. A lógica da ação coletiva: os benefícios públicos e uma teoria dos grupos sociais. São Paulo: Edusp, 1999. $208 \mathrm{p}$

OSTROM, E. Understanding institutional diversity. Princeton: Princeton University Press, 2005. 355 p.

Governing the commons: the evolution of institutions for collective action. New York: Cambridge University Press, [1990] 2006. 280 p

The challenge of crafting rules to change open access resources into managed resources. In: TEIXEIRA, E. C.; BRAGA, M. J. Instituições e desenvolvimento econômico. Viçosa,MG: Departamento de Economia Rural/ Universidade Federal de Viçosa, 2007a. 349 p.

The governance challenge: matching institutions to the structure of social-ecological systems. In: TEIXEIRA, E. C.; BRAGA, M. J. Instituições e desenvolvimento econômico. Viçosa,MG: Departamento de Economia Rural/Universidade Federal de Viçosa. 2007b. 349p.

; MORAN F. E. Ecossistemas florestais. São Pauo: SENAC / EDUSP. 2009. 544 p.

SARTORI, G. A política. Brasília: Editora UNB, 1997. 257 p.

SYLOS LABINI Saggio sulle classi sociale. Bari: Laterza, 1988. $196 \mathrm{p}$

Torniamo ai classici: produtività del lavor, progresso técnico e sviluppo econômico. Bari, Laterza, 2006. $164 \mathrm{p}$.

Miséria e sottosviluppo. Come Uscirne. Milano: Il Sole 24 Ore Pirola, 2007. 71p.

WEBER, M. Economia y sociedad. México: Fondo de Cultura Económica, 1997. 1237p.

The protestant ethic and the spirit of capitalism. London: Unwin Paper Backs, 1985. 292 p. $\overline{530 \mathrm{p} .}$

Ensaios de sociologia. Rio de Janeiro, Zahar, 1979. $\overline{342 \mathrm{p} .}$

Storia econômica. Roma: Donzelli Editore, 2007. 


\section{ELINOR OSTROM, THE AWARDING OF AN UNIFIED VISION OF HUMAN SCIENCES}

\section{Amilcar Baiardi}

There were always concerns regarding the establishment of a paradigmatic and historical connection between sociology, economy and politics, supporting the unification of these scientific fields and bringing back what to Weber was Social Sciences as "Science of Reality", aimed at understanding the current cultural significance of phenomena and to the understanding of its historical origin and that, for Marx, was the pursuit of wholeness, of paramount importance because it would not be possible to understand the parts without a vision of the whole. In this text, one explores this approach, focusing on the work of Elinor Ostrom, winner of the Nobel Prize in Economics in 2009, who has always refused to see the sphere of human sciences as a "Tower of Babel," but rather as an environment with ample opportunity for integration, their praxis being a full and eloquent example of convergence and synthesis in the social sciences. After a brief examination of some emblematic cases of attempted integration of the social sciences, one analyzes the academic career of Elinor Ostrom and her major contributions to research on the resources and assets under common ownership.

KEYWORDS: common property, cooperation, interdisciplinarity, institutions and governance.

\section{ELINOR OSTROM, PRIX DE LA VISION UNIFIÉE DES SCIENCES HUMAINES}

\section{Amilcar Baiardi}

La préoccupation d'établir un lien historique et paradigmatique entre la sociologie, l'économie et la politique a toujours existé. Elle soutient l'unification des domaines scientifiques et rapporte ce qu'étaient pour Weber les Sciences Sociales, les "Sciences de la Réalité", tournées vers la compréhension de la signification culturelle actuelle des phénomènes et celle de son origine historique qui, pour Marx, était la recherche du tout, fondamental, car il est impossible d'en comprendre les parties sans avoir une perception de l'ensemble. On explore, dans ce texte, cette 'approche' en focalisant l'œuvre de Elinor Ostrom, Prix Nobel d'Économie en 2009, qui n’a jamais voulu considérer la sphère des Sciences Humaines comme une "Tour de Babel" mais au contraire comme un environnement rempli de possibilités d'intégration, sa praxis étant un exemple complet et éloquent de convergence et de synthèse des sciences sociales. Après avoir brièvement examiné quelques cas emblématiques de tentatives d'intégration des sciences sociales, on fait l'analyse de la carrière universitaire de Elinor Ostrom et de ses contributions majeures apportées à la recherche concernant les ressources et les actifs de propriétés communes.

MoTs-CLÉs: propriété commune, coopération, interdisciplinarité, institutions et gouvernance.

Amílcar Baiardi - Doutor em Ciências Humanas pela Universidade Estadual de Campinas. Professor titular da Universidade Federal do Recôncavo da Bahia. Professor permanente do programas de pósgraduação da Universidade Federal da Bahia em Ensino, Filosofia e História da Ciência, PGEFIHC e coordenador do Programa de Pós-Graduação em Ciências Sociais da Universidade Federal do Recôncavo da Bahia. Bolsista de Produtividade de Pesquisa do CNPq. Coordenador de comitê assessor do CNPq para projetos do fundo setorial de agonegócios, avaliador de pós graduação stricto sensu da CAPES. Atua em ensino e pesquisa na área de Ciências Sociais, com ênfase em Políticas de Ciência e Tecnologia, História da Ciência, Políticas Públicas, Desenvolvimento Rural e Regional, Capital Social e Valores para a Cooperação Produtiva, procurando enfocar as determinantes e condicionantes de intervenções desenvolvimentistas na esfera do Estado e na esfera da sociedade civil. 